\title{
Pattern and Direction of Microstrain in Q\&T Steel Weld Joint
}

\author{
Yurianto $^{1, *}$, Pratikto $^{1}$, Rudy Soenoko ${ }^{1}$, Wahyono, Suprapto ${ }^{1}$ and Sulardjaka ${ }^{2}$ \\ ${ }^{1}$ Brawijaya University, Mechanical Engineering Department, Malang 65145, East Jawa, Indonesia \\ ${ }^{2}$ Diponegoro University, Mechanical Engineering Department, Semarang 50275, Central of Java, Indonesia
}

\begin{abstract}
The welded joint always contains the microstrain when welding is complete. The microstrain generates distortion and changes of the physical shape of the weld joint. The purpose of the study was to observe the pattern and direction of residual stress before and after welding $\mathrm{Q}_{900} \& \mathrm{~T}_{125}$ and $\mathrm{Q}_{900} \& \mathrm{~T}_{175}$ Steel. The materials used for this study is Hot Rolled Plate Steel made by Indonesia steel industry. Method of this study is $1 . \mathrm{Q}_{900} \& \mathrm{~T}_{125}$ and $\mathrm{Q}_{900} \& \mathrm{~T}_{125}$ Steel machined in V-butt joint. This joints weld by using manual gas metal arc welding, $\mathrm{Q}_{900} \& \mathrm{~T}_{125}$ and $\mathrm{Q} 900 \& \mathrm{~T}_{125}$ Steel weld joint can be found. 2. Measuring the distance from the lattice planes before and after welding by using Neutron-Ray Diffraction. Then the microstrain can be found. By involving Poisson numbers and modulus of elasticity of material in microstrain obtained residual stress. All the pattern of microstrain is compressive stress and leads to the weld center.
\end{abstract}

\section{Introduction}

Connecting two or more metals at their melting temperature with or without pressure is known as welding. Welding arc causes the melting metal to expand and solidify in atmospheric cooling. From this, there will be a microstrain that is permanently left over during freezing.

Arc welding causes the expansion and fusion of two base metals to be welded and leaving the stress called residual stress. This stress can be reduced by temper heat treatment at $150 \mathrm{oC}$, and cooled in the atmosphere [1]. Thermal cycle causes non-uniform heating and cooling in metal, and creating inhomogene-ous plastic deformation and residual stress in the welds. [2]. While the maximum residual stress occurs in heat affected zone, that is tension residual stress [3]. The voids formed at the grain boundary and the residual stress of the welding process will affect the crack growth [4]. The significant amounts of the tensile stress were developed not along the weld centerline but along the heat-affected zone of the weld [5]. In Quenched and Tempered Steel is obtained that quench and temper heat-treated on hot rolled plate steel leaves residual stresses. The cooling rate increases, the tensile residual stress of the surface rises and decreases the compressive residual stress [6]. The remaining compressive stress is often used to inhibit crack initiation and growth. Thus increasing the range of crack growth and decreasing the growth rate [7]. Meanwhile, the residual stresses are the most manufacturing processes involving the deformation of a material [8]. The residual stress of welding has an impact on the performance of welded structures, fracture resistance, resistance to fatigue crack propagation, fatigue strength and fatigue period [9]. The residual stress has a strong effect on the performance of the product. Therefore, the residual stress produced during the manufacturing process must consider in the design stage [10]. Complex structures assembled of thickwalled components welded by multi-pass welds. Repeated heat exposures HAZ are subjected by cumulative thermo-mechanical influences. This affecting complex microstructural transformations changes in local thermo-mechanical properties and the development of residual stresses [11]. On the other hand, the residual stress can be used to predict fatigue crack propagation on rigid panel welds for the effect of residual stress [12]. Greater tensile stress at the upper surface of the weld [13].

In the welding process, strain arises because the metal expands when it melts and solidify when cooling. This strain, when involved by Poisson number and elastic modulus of the material, will be obtained stress. This stress is permanently left behind while freezing and known residual stress. The internal strain can be obtained by measuring the distance between the standard lattice grid (considered free stress) to stressed sample and calculated by

$$
\varepsilon=\frac{d-d_{0}}{d_{0}}
$$

The basic principle of residual stress calculation is based on Bragg Law [14]

$$
n \lambda=2 \times d \times \sin \theta
$$

Where,

$\boldsymbol{\varepsilon}=$ Strain of the sample crystal lattice.

$\mathrm{d}_{\mathrm{o}}=$ Distance between free stress sample crystal lattice.

$\mathrm{d}=$ Distance between stressed sample crystal lattice.

$\mathrm{n}=$ Constants

$\lambda=$ Wavelength. 


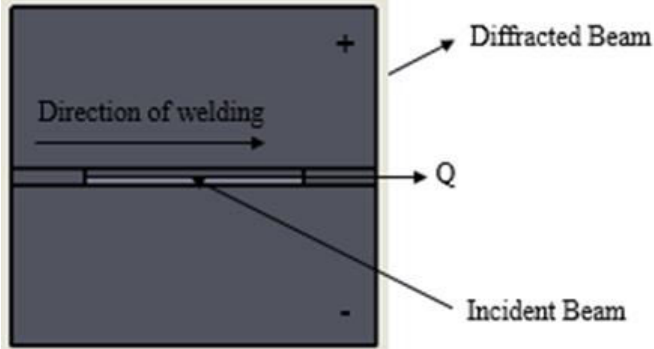

(a) Axial direction

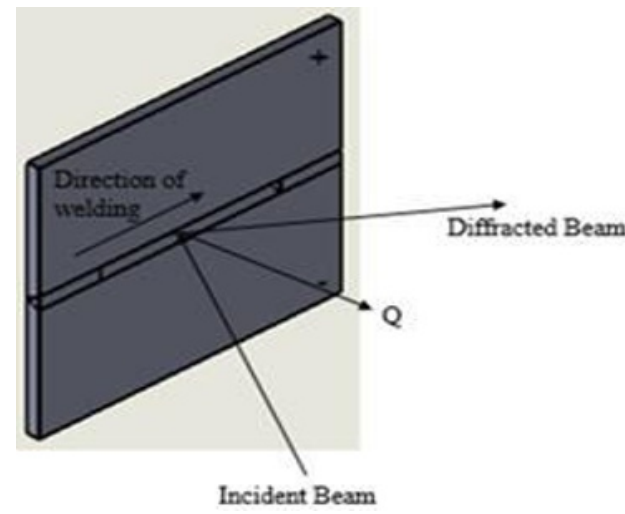

(c) Normal direction

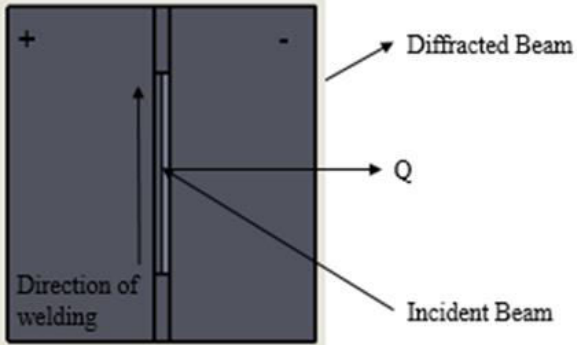

(b) Transversal direction

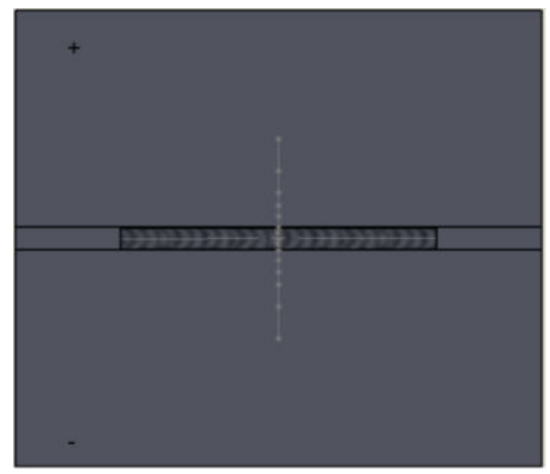

(d) Residual stress measurement

Fig. 1. Schematic diagram for position of the sample to neutron beam direction of measurement [15]

Fig. 2. V butt joint

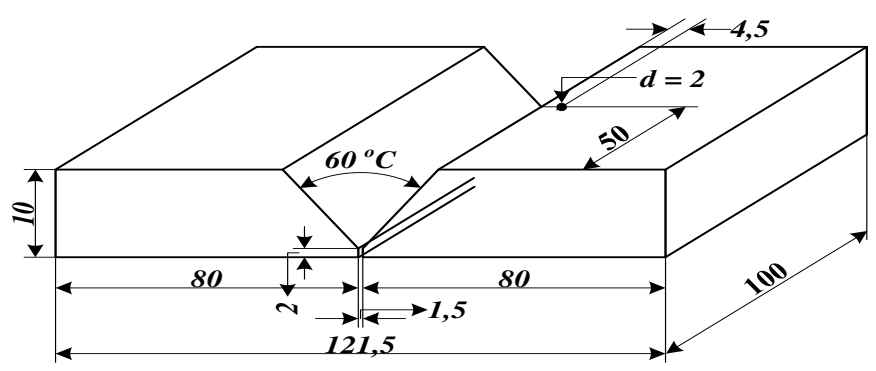

Residual stress on $\mathrm{x}, \mathrm{y}$ dan $\mathrm{z}$-axis is written by

$$
\begin{aligned}
& \sigma_{x}=\frac{E}{\{1+v(1-2 v)\}} \\
& \sigma_{y}=\frac{E}{\left\{(1-v) \varepsilon_{x}+\mathbf{v}\left(\varepsilon_{y}+\varepsilon_{z}\right)\right\}} \\
& \sigma_{z}=\frac{\left\{(1-v) \varepsilon_{y}+\mathbf{v}\left(\varepsilon_{x}+\varepsilon_{z}\right)\right\}}{\{1+v(1-2 v)\}} \\
& \left\{(1-v) \varepsilon_{z}+\mathbf{v}\left(\varepsilon_{x}+\varepsilon_{y}\right)\right\}
\end{aligned}
$$

Where:

$\sigma_{\mathrm{x}}=$ Axial stress on $\mathrm{x}$ axis

$\sigma_{\mathrm{y}}=$ Transversal stress on $\mathrm{x}$ axis.

$\sigma_{\mathrm{z}}=$ Normal stress on $\mathrm{z}$ axis.

The aim of this study to observe the pattern and direction of residual stress before and after welding of $\mathrm{Q}_{900} \& \mathrm{~T}_{125}$ Steel and $\mathrm{Q}_{900} \& \mathrm{~T}_{175}$ Steel.

The benefit of this study is to anticipate the loading direction to be opposite to the residual stress direction.

\section{Material and Method}

The material used in this study is Hot Rolled Plate Steel - HRP Steel, thick $10 \mathrm{~mm}$. This steel made by PT. Krakatau Steel (Persero), Cilegon, Banten, Indonesia on 2008.

The material for the research was prepared with the appropriate shape as shown in Figure 1. Determine the position and direction of welding used for the purpose measuring the residual stresses. The shape of the joint used in this research is a butt-joint as shown in Figure 2. The welded joint used in this research made by using manual gas metal arc welding - MGMAW. To prevent changes in connection shape due to the welding process is used the fixture.

The method used is measurement the microstrain of weld joint by using Neutron Ray Diffraction in weld and base metals before and after the welding is complete. Neutron-Ray diffracttometer measures the distance 


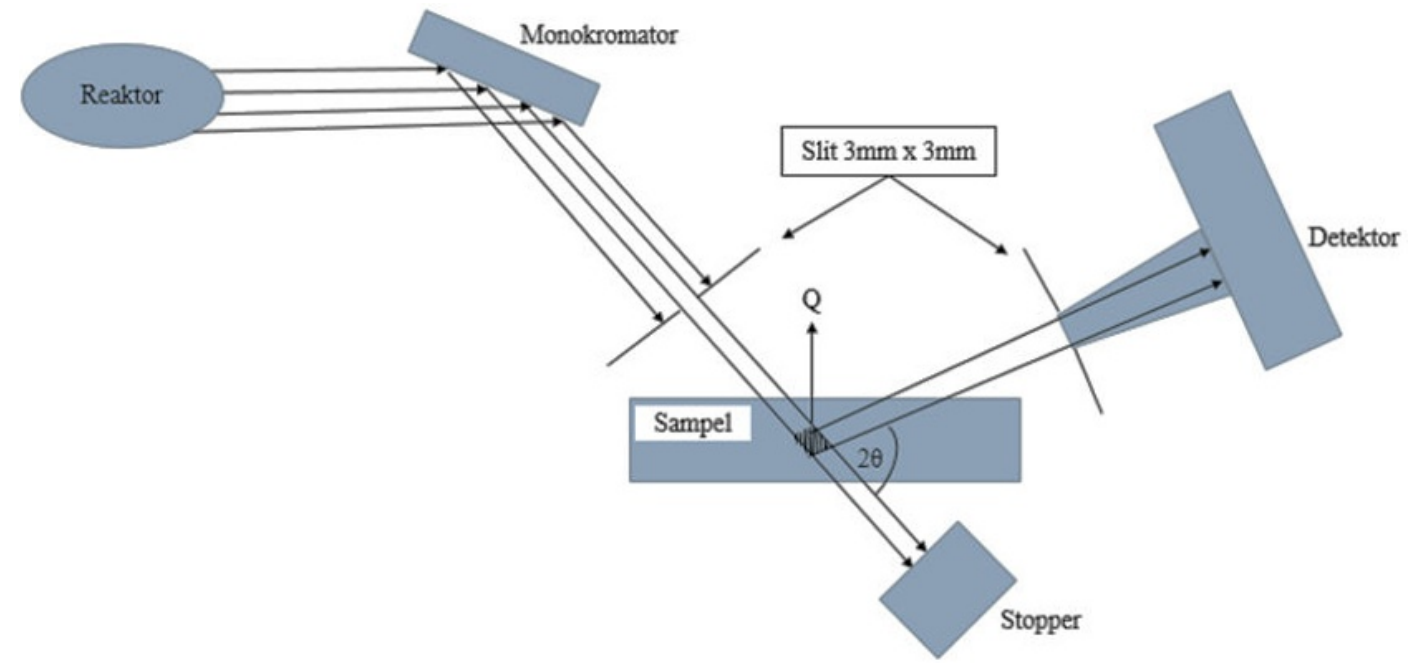

Fig. 3. Schematic diagram of Neutron Diffractometer [15]

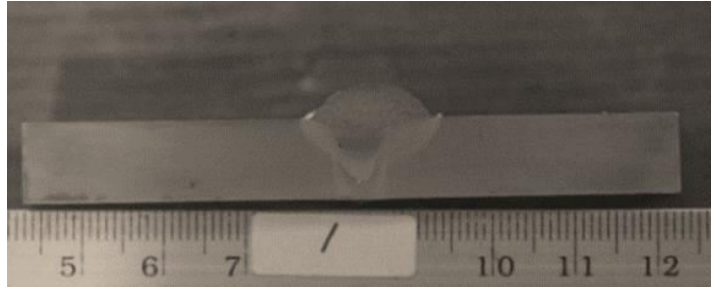

(a) Fixture used

Fig. 4. Manual Gas Metal Arc Welded Joint

between the stressed lattice (d) and free stress (do). From $\mathrm{d}$ and do can be obtained the strain in each direction (axial, normal and transverse). Based on Hooke's Diagram modulus of elasticity can be obtained.

Neutron diffractometer used in this study shown in Figure 3, and residual stress measurement is: [15]

1. Setting zero to place the sample table on $X, Y$, and $Z$ axis on the same zero position when the ray at the end of the jig, turn the sample table to $180^{\circ}$.

2. Calibrate on detector arm to obtain the regression equation to change of channel number to $2 \theta$.

3. Calibrate with Si 640d to determine the absolute point of the detector arm and the wavelength was obtained from the measurement $2 \theta$ (Bragg equation) and the $\mathrm{d}_{\mathrm{hkl}}$ in each silicon plane. Calibration by using standard samples of Silicone 640d powder measured on (111), (220), (311), (400), and (331) planes.

4. Determine the slit size of scattered neutron beam and the region of residual stress measurement (Figure 1). The slits used to measure the residual stress is $3 \mathrm{~mm} \times$ $3 \mathrm{~mm}$.

5. Position the sample to be strain measured by setting the table, and make sure position and set the sample on the table.

6. Measurement $d_{o}$ of strain-free base metal and in one direction. For measurement of the stressed condition is conducted on (211) plane with scatter angle $103^{\circ}$.

7. The sample measurements of $d$ were carried out under normal conditions and welded. The strain measurements were conducted on the plane (211) by a scatter angle of about $103^{\circ}$ in the axial, transverse, and normal directions. The samples were measured $1 \mathrm{~mm}$, $4 \mathrm{~mm}, 7 \mathrm{~mm}, 9 \mathrm{~mm}, 11 \mathrm{~mm}, 16 \mathrm{~mm}, 30 \mathrm{~mm}$, and $50 \mathrm{~mm}$

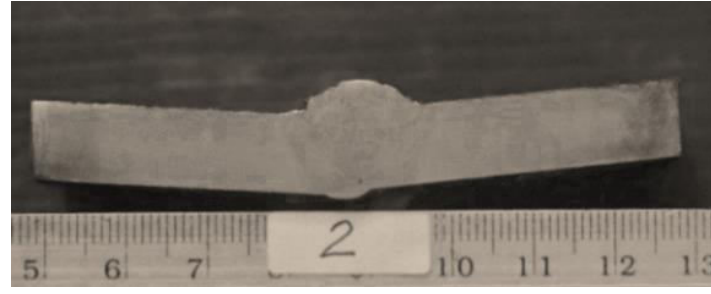

(b) Without fixture used

of the weld center line.

8. Measurement analysis of original stress and strain of neutron diffractometer is the relation between channel number and intensity. By using genuine software to get the peak value from the measurement results, change the value of the channel number to $2 \theta$ by regression equation from the calibration of the detector arm. The strain value can be obtained by Bragg equation. By using Hooke's Law, Young Modulus $20 \times 1010(\mathrm{~Pa})$ and Poisson ratio 0.24 the residual stress will be obtained for each direction.

\section{Results and Discussion}

The axial strain is in the direction of the motion of the electrode (welding motion). The normal strain is perpendicular to the welding motion. the transverse strain sideways and toward the weld axis. The direction of the transversal strain is sideways direction to the welding center (freezing direction). Tensile stress is susceptible to crack and stress release required by using temper heat treatment at about $150^{\circ} \mathrm{C}$ and held about 30 to 45 minutes. Axial, normal and transverse stress is stress left permanently in the weld joint and called axial, normal and transverse residual stress respectively.

Figure 4(a) shows the surface of joint due to the welding process and held by the fixture (flat). The pull of the melt metal surface when cool (solidified) is held by the fixture. In Figure 4(b) shows a curved joint (surface attracted to weld center line). Its caused by the presence of welded metal shrinking due to freezing after welding is complete (cooling). The pull of the solidified metal 
surface is not held by the fixture (two base metals are attracted to the center of the weld by metal solidification).

Figure 5(a) shows the pattern and direction of the Q\& $T_{125}$ Steel residual stress before welding. Normal, axial and transverse stress direction is random and produced by prior quench and temper when making of

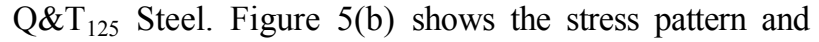
direction of Q\& $\mathrm{T}_{125}$ Steel after welding is complete. The axial, normal and transverse stress generated by solidification of weld metal. Axial stress increase and decrease at the weld center. The normal is higher than the transverse strain. All stress decreases and concentrated in the weld center. So all residual stress at the center of the weld is the compressive residual stress.

Figure 6(a) shows the pattern and direction of the stress of Q\&T 175 Steel before welding. The stress on by quenching and tempering when making of $Q \& T_{175}$ Steel. The stress pattern has changed (than Q\&T 125 Steel) because of temper process at $175^{\circ} \mathrm{C}$. Stresses are the

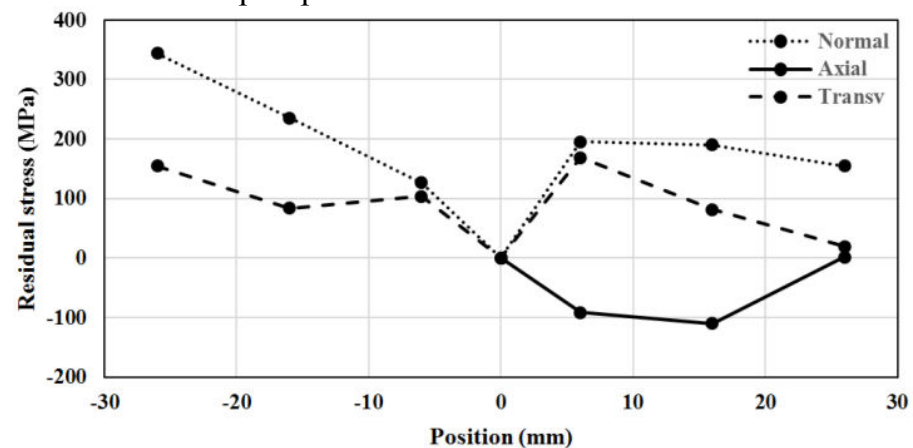

(a) Before welding

Fig. 5. $Q \& T_{125}$ Steel Residual Stress

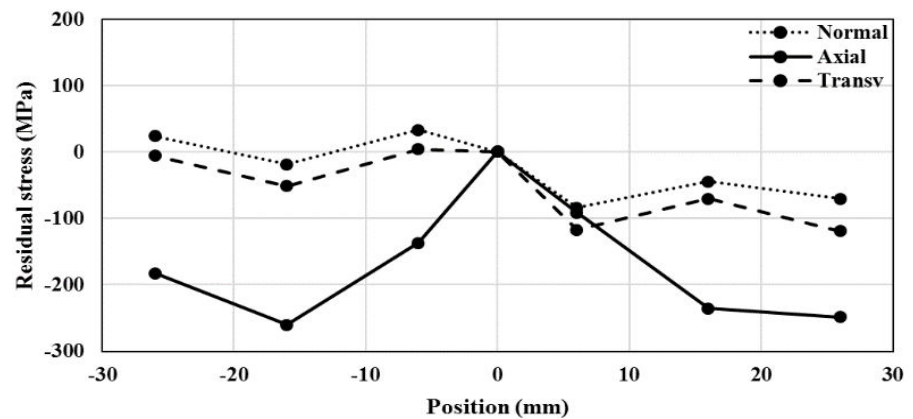

(a) Before welding compressive. Normal and transverse stress decrease to the center of the weld, these stress are compressive. Figure 6(b) shows the pattern and direction of the stress of Q\&T ${ }_{175}$ Steel after welding is complete. Axial stress rises and decreases at the weld center. Normal and transverse stress decrease to the center of the weld, these stress are compressive.

Figure 7 Shows the axial stress on Q\& $\mathrm{T}_{125}$ Steel and

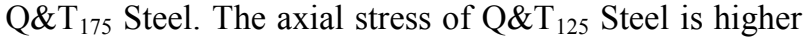
than $Q \& T_{175}$ Steel, and both stresses concentrate on the weld center. These stress cause shrinkage during cooling, and resulting in the concave surface at the boundary between the weld metal and the base metal (causing a stress concentration).

Figure 8 shows the normal stress on Q\&T ${ }_{125}$ Steel and $Q \& T_{175}$ Steel, both stresses are concentrating at the weld center line. These stress cause shrinkage during cooling and produce a concave surface at the boundary between the weld metal and the base metal.

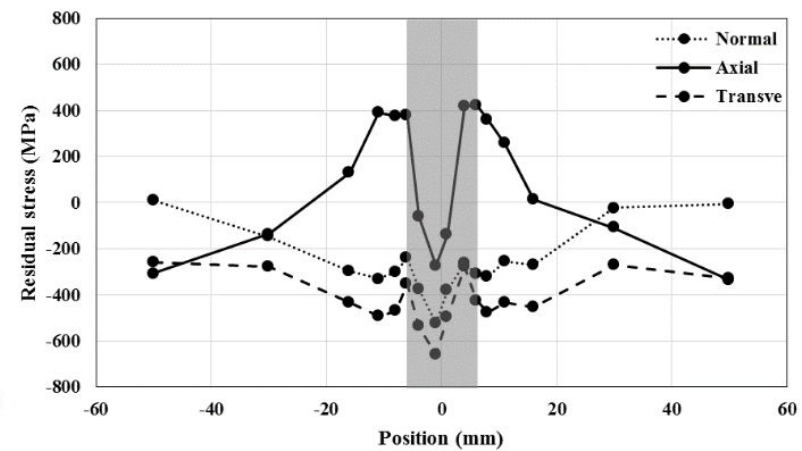

(b) After welding

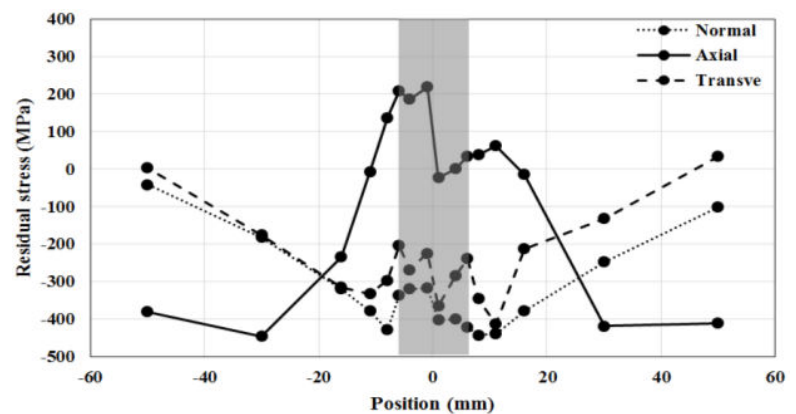

(b) After welding

Fig. 6. $Q \& T_{175}$ Residual stress

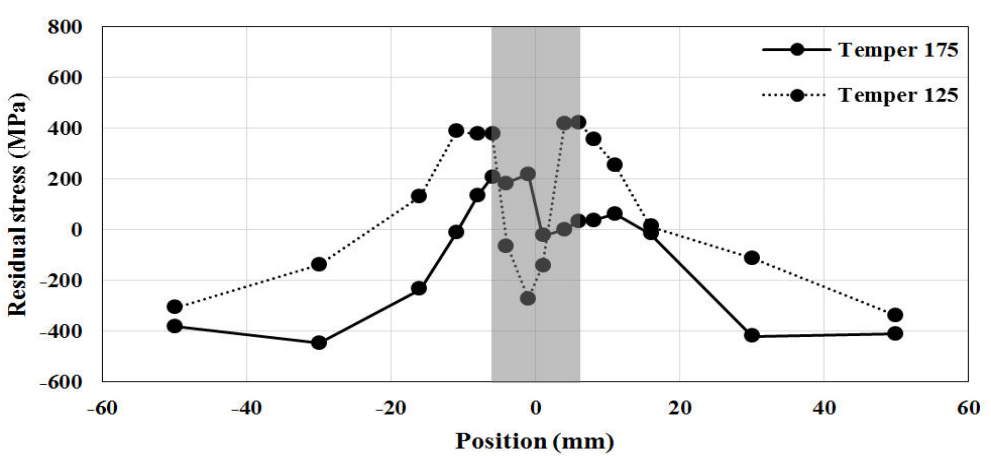

Fig. 7. Axial Residual stress 


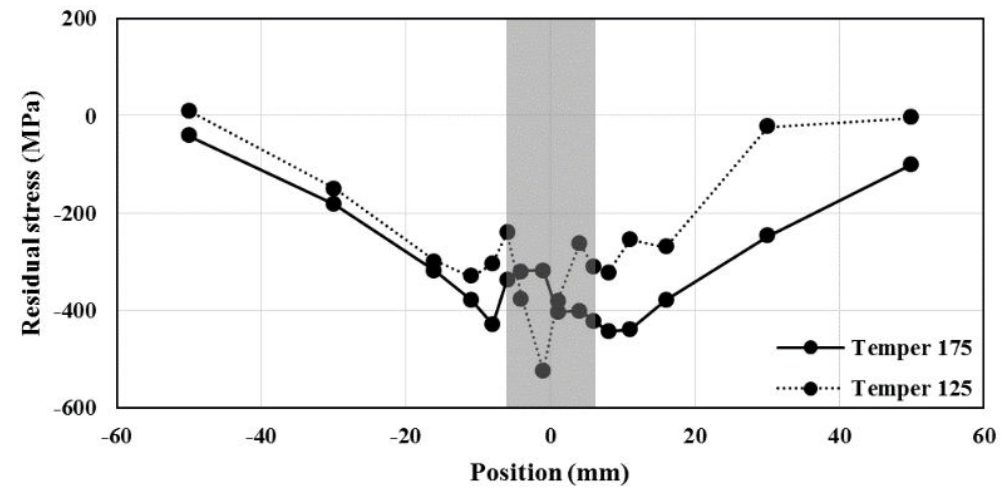

Fig. 8. Normal Residual stress

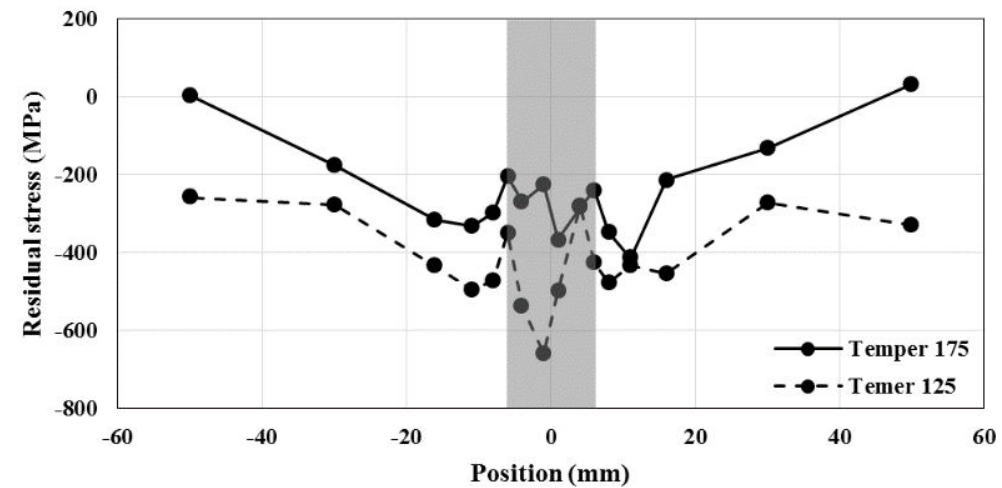

Fig. 9. Transverse Residual stress

Figure 9 shows the pattern and directions of a transversals stress of after welding is complete, and both are similar stress. The stress on $Q \& \mathrm{~T}_{125}$ and Q\& $T_{175}$ Steel is the compressive stress causes the weld surface to be attracted to the welding center.

During the welding process produces a melt mixture between the electrodes and the base metal, and freezes to produce welded joints. The melting of weld metal produces a concentrated shrinkage in the center of the weld. Shrinkage caused by normal, axial and transverse stress and produced compressive stress by solidifying of melt of weld metals.

Residual stress can't be neglected but reduced by using heat treatment when welding is complete, suitable by using temper at about $150^{\circ} \mathrm{C}$ as recommended by George Krauss [1]. Our experience shows heating above $150^{\circ} \mathrm{C}$ will soften the joint and decrease its strength. Especially for Quenched and Tempered Steel which retains the martensite structure.

The compression stress in the weld joint increases the microstructure density and directly increases the hardness. But on the other hand that the non-melting metal will hold it, and the interface between the solid and melting zone is the tensile stress.

Tensile stress is susceptible to crack and stress release required by using temper heat treatment at about $150^{\circ} \mathrm{C}$ and held about 30 to 45 minutes

Heating when welding is completed can reduce the cooling rate and risk of the crack in welds, this heating called by post weld heat treatment - PWHT. PWHT is useful to prevent martensite formed by fast cooling (quenching). The martensite structure causes the increase in the hardness of the weld metal. The brittle weld metal caused by excessive hardness and reduce the strength of welded joints.

Compressive stress cause hardening by density increased in the microstructure and called mechanical hardening. Compressive stress causes decreased ductility and is said to be a brittle material.

Another effect of compressive stress is in the heat affected zone - HAZ. HAZ consists of a coarse grain HAZ - CGHAZ (adjacent to weld metal) and fine grains HAZ - FGHAZ (adjacent to base metal) and intercritical HAZ - ICHAZ. The compression stress experienced by three HAZs each has a different density, and CGHAZ has the lowest microstructure density (highest grain size in HAZ).

CGHAZ is a layer consist of a rough microstructure, and this causes the weld strength decreases. Therefore, the grain structure is made uniformly by using buttering welding (e. replacing CGHAZ with a new layer). It is expected to produce the weld joints of uniform grain structures.

\section{Conclusions}

The study has been done using Neutron-Ray Diffraction can be concluded as follows,

Microstrain causes the shrinkage on the weld metal surface to be concave.

The pattern of residual stress is random and always leads to the center of the weld (due to solidification effect), and cause excessive hardening by the density increase.

The strength of the weld joint decreases due to the tension zone at the interface between the unmelt base 
metal and the melted base metal. Tension zone is a crack triggering of the weld joint.

The stress in HAZ is similar to other areas (compressive stress), and the decrease in strength of joint.

The compression residual stress is suitable to resist the tensile loads.

This study was funded by a research grant of PDUPT (Penelitian Dasar Unggulan Perguruan Tinggi), Simlitabmas Kemenristek Dikti. The authors would like to thank Mr. Amung Somantri when he was Manager for Materials and Product Development and his staff PT. Krakatau Steel (Persero) Cilegon, Banten, Indonesia for supporting materials for this study.

\section{Refferences}

1. Krauss, George.,1999, Martensite in steel: strength and structure, Materials Science and Engineering A273-275 (1999): 40-57.

2. S. Murugan, Sanjai, K. Rai, P.V. Kumar, T. Jayakumar, Baldev Raj, M.S.C. Bose, Temperature distribution and residual stress due to multi-pass welding in type 304 stainless steel and low carbon steel weld pad, International Journal of Pressure Vessels and Piping 78 (2001), 307 - 317.

3. Yurianto, Pola Tegangan Sisa Sambungan Las Rel R54 Hasil Pengelasan Thermite (Residual Stress Patern on Rail R54 Weld Joint Produced by Thermite Welding), Prosiding Seminar Nasional VII Rekayasa dan Aplikasi Teknik Mesin di Industri, TBMK-21, Bandung, 28-29 Okt.r 2008, ITENAS.

4. J.C. Chang, B.S. Kim and N.H. Heo, Stress Relief Cracking on the Weld of T/P 23 Steel, Procedia Engineering 10 (2011) 734-739

5. Wanchuck Woo, Vyacheslav Em, Pavel Mikula, Gyu-Baek An, Baek-Seok Seong, Materials Science and Engineering A 528 (2011) 4120-4124.

6. Zhihao Zhang, Wenping Wang, Huadong Fu, Jianxin Xie, Materials Science and Engineering A 530 (2011) 519-524.

7. Christopher J. Lammi and Diana A. Lados, International Journal of Fatigue 33 (2011) 858-867.

8. N.S. Rossini, M. Dassisti, K.Y. Benyounis, A.G. Olabi, Methods of measuring residual stresses in compo-nents, Materials and Design 35 (2012) 572588.

9. J. Hensel, T. Nitschke-Pagela, D. Tchoffo Ngoula, H.-Th. Beier, D. Tchuindjang, Welding residual stresses as needed for the prediction of fatigue crack propagation and fatigue strength, Engineering Fracture Mechanics (2017). https://doi.org/10.1016/j.engfracmech.2017.10.024.

10. Si Young Kwak and Ho Young Hwang, Effect of heat tre-atment residual stress on stress behavior of constant stress beam, Journal of Computational Design and Engineering (2017), https://doi.org/10.1016/j.jcde.2017.07.001.

11. Gancho Genchev, Nikolay Doynov, Ralf Ossenbrink, Ves-selin Michailov, Gizo Bokuchava, Peter Petrov, Residual stresses formation in multi-pass weldment: A numerical and experimental study, Journal of Constructional Steel Research 138 (2017) 633-641.

12. Željko Božić, Siegfried Schmauder, Hinko Wolf, The effect of residual stresses on fatigue crack propagation in welded stiffened panels, Engineering Failure Analysis (2017), doi: 10.1016/j.engfailanal.2017.09.001.

13. Luis D. Cozzolino, Harry E. Coules, Paul A. Colegrove, Shuwen Wen, Investigation of postweld rolling methods to reduce residual stress and distortion, Journal of Materials Processing Tech. 247 (2017) 243-256.

14. Cullity, B.D., (1978), Elements of X-Ray Diffraction, 2nd Edition, Addison-Wessley Publishing Company, Inc., Reading, Massachussetts, 447-453.

15. Cepie Cahyana, (2018), Analysis of Residual Stress for Indonesia Q\&T Steel Before and After GMAW Welding Using Neutron-Ray Difraction (Indonesian), Bachelor Theses, Mechanical Engineering Department, Faculty of Engineering, Diponegoro University, Indonesia.

16. Dieter, George E., 1988, Mechanical Metallurgy, SI Metric Edition, McGraw-Hill Book Company (UK) Limited. 